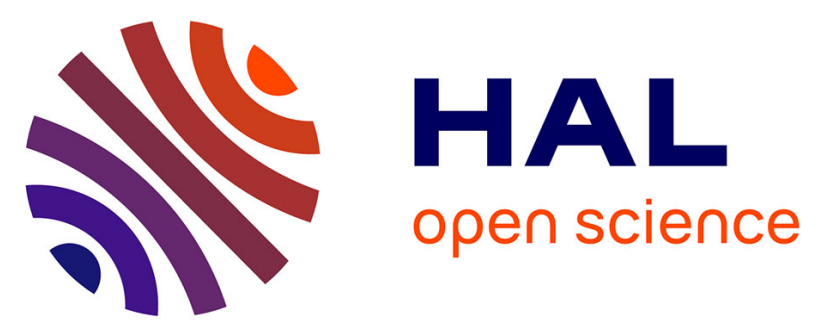

\title{
Benefits in noise from sound processor upgrade in thirty-three cochlear implant users for more than 20 years
}

Isabelle Mosnier, Olivier Sterkers, Yann Nguyen, Ghizlene Lahlou

\section{- To cite this version:}

Isabelle Mosnier, Olivier Sterkers, Yann Nguyen, Ghizlene Lahlou. Benefits in noise from sound processor upgrade in thirty-three cochlear implant users for more than 20 years. Archives of otorhino-laryngology, 2020, 10.1007/s00405-020-06144-y . hal-03018728

\section{HAL Id: hal-03018728 \\ https: / hal.sorbonne-universite.fr/hal-03018728}

Submitted on 23 Nov 2020

HAL is a multi-disciplinary open access archive for the deposit and dissemination of scientific research documents, whether they are published or not. The documents may come from teaching and research institutions in France or abroad, or from public or private research centers.
L'archive ouverte pluridisciplinaire HAL, est destinée au dépôt et à la diffusion de documents scientifiques de niveau recherche, publiés ou non, émanant des établissements d'enseignement et de recherche français ou étrangers, des laboratoires publics ou privés. 


\section{Benefits in noise from sound processor upgrade in thirty-three cochlear implant users for more than 20 years}

Isabelle Mosnier, MD; Olivier Sterkers, MD, PhD ; Yann Nguyen, $\mathrm{MD}, \mathrm{PhD}$; Ghizlene Lahlou, MD

Sorbonne Université-APHP6, Groupe Hospitalo-Universitaire Pitié-Salpêtrière, Service ORL, Unité fonctionnelle Implants auditifs, Paris, France.

Corresponding author : Isabelle Mosnier, MD

GHU Pitié-Salpêtrière, UF Implants auditifs et explorations fonctionnelles, Bâtiment Paul Castaigne,47-83 Boulevard de l'Hôpital, 75013 Paris, France

email : isabelle.mosnier@aphp.fr

phone : +(33) 142162606

fax : +(33) 142162605

Running Title: Cochlear implant for life.

No conflict of interest

No funding.

Written informed consent was obtained from each subject before enrolment into the study (CNIL n² 2040853v0).

Acknowledgements: We gratefully acknowledge the help of Solange Lator for assistance in data collection. 


\section{Abstract}

Purpose: Some oldest patients rehabilitated with a cochlear implant more than 20 years ago could still be upgraded with new generations of speech processor (SP). The aim of this study was to show the benefit of a recent generation of SP in this population.

Methods: A monocentric prospective study was designed to evaluate the performance of 33 ancient CI22M users implanted between 1989 and 1997 and upgraded with the late compatible sound processor CP900. Performance were evaluated in quiet and noise with Framatix, an automated adaptative test.

Results: Performance using Framatix significantly improved with the CP900, with a decrease of the median speech perception threshold of $6 \mathrm{~dB}$ in quiet $(p<0.05)$ and $5,3 \mathrm{~dB}$ in noise $(p<0.0005)$. No subjective benefit using the $A P H A B$ questionnaire was observed.

Conclusion: Upgrading of cochlear implant recipients who were implanted more than 20 years ago with recent compatible and new technological SP provide benefit in speech recognition in noise.

Key words: long-term benefit, hearing in noise, upgrading, speech processor. 


\section{Introduction}

Deafness has been established to play a key role on cognitive functions all along the life, as early deafness restoration permits development of language [1], deafness at mid-age is the main modifiable factor for dementia [2], and profoundly deaf rehabilitation by cochlear implant $(\mathrm{Cl})$ in elderly reduces dramatically cognitive impairment and its evolution to dementia [3]. Multichannel $\mathrm{Cl}$ available since the late 1980 s has changed the life of severe to profoundly deaf people [4], who would further gain benefit from new technologies by upgrading the external sound processor (SP). New SP generation has improved dramatically Cl performance in noise intelligibility for most patients [5-7]. However, some oldest $\mathrm{Cl}$ implanted more than 20 years ago could not be upgraded with new SPs due to the lack of compatibility for some brands of $\mathrm{Cl}$. It raised the question of surgical reimplantation of the internal part in this population which would have concerned at most more than 600 recipients implanted before 2000 in France. The aim of this study was to show the benefit of a recent generation of SP in the oldest $\mathrm{Cl}$ population.

\section{Methods}

A monocentric study was prospectively conducted on $\mathrm{Cl}$ recipients, implanted between 1989 and 1997 with the first generation of $\mathrm{Cl}$ (CI22M, Cochlear, Sydney, Australia), to test the benefit of the more recent compatible SP (CP 900). Among 63 implanted patients, 17 were either lost of follow-up or deceased, 11 others were not eligible for a reimbursement of a new SP, and 2 had incomplete data. Finally 33 daily $\mathrm{CI} 22 \mathrm{M}$ users for $21 \pm 2.2$ years (range: $19-26)$ were included. Among them, 16 pre-lingual, 2 peri-lingual, and 15 post-lingual subjects with a profound to total hearing loss were implanted at 5 years (range: $3-16$ ), at 37 and 38 years, and 
at 36 years (range: 16-60), respectively. Demographic data of the population are described in Table 1. The current SP at the time of the upgrade was a Freedom and an ESPrit 3G SP for 31 and 2 subjects respectively, and all of them used the SPEAK coding strategy. Characteristics of the three generations of SP were indicated in Table 2. The CP 900 SP was fitted with the same SPEAK strategy and the same MAP characteristics as was used in the original processor. Three programs were available: 2 new automatic signal processing algorithm programs (SCAN) and a nonSCAN program with the same options used as in the original SP (Table 1). Cl users were tested with their current revised SP, and at 2 months post-upgrade with the CP900 with their preferred program, in a soundproof room with two lists of monosyllabic words presented at $60 \mathrm{~dB}$ SPL in quiet (Lafon list) and for the best performers, with an automated adaptive test in quiet and noise (Framatrix [8]), with the current revised SP and the CP900 at 2 months post-upgrade. Subjective perceptions were evaluated using the Abbreviated Profile of Hearing Aid Benefit (APHAB) questionnaire [9]. The results for each test session were compared independently. Scores for words in quiet, the Framatrix test and the APHAB questionnaire were not normally distributed, so a non-parametric Wilcoxon paired test were used. A p value of less than 0.05 was considered to be significant.

\section{Results}

Two months after upgrading first generations of internal receiver $(\mathrm{CI} 22 \mathrm{M})$ with the CP900 SP, 31 out of the 33 patients used the SCAN programs all day long (Table 1). No change was observed in quiet for median scores of words (41\% vs $43 \%)$ and phonemes $(72 \%$ vs $67 \%)$ recognition of the monosyllabic words list. Using adaptive test,speech reception threshold measurement in quiet was feasible before upgrading, in 18 out of $33 \mathrm{Cl} 22 \mathrm{M}$ recipients in quiet (54\%) and 13 out of these 18 
patients in noise (39\%). In this population, the median speech reception threshold was decreased by $6 \mathrm{~dB}$ (range: $-27,+5 ; \mathrm{p}<0.05$ ) with CP900 as compared to previous SP (Fig. 1A). In noise, it decreased with CP900 by $5.3 \mathrm{~dB}$ (range: -16, -0.4; $\mathrm{p}<0.0005)$ as compared to older SP, and even became measurable at $+12.4 \mathrm{~dB}$ in 6 other subjects (Fig. 1B). The benefit in noise was observed in pre-lingual and in post-lingual $\mathrm{CI} 22 \mathrm{M}$ recipients. $\mathrm{APH} A B$ scores were available before and after upgrading in 30 out of $33 \mathrm{Cl} 22 \mathrm{M}$ recipients and was unchanged with the CP900 SP (Fig. 2).

\section{Discussion}

Over the last 15-20 years, the series of SPs from Cochlear Limited has introduced a number of refinements designed to enhance $\mathrm{Cl}$ performance mainly in noise. The processor CP810, introduced with the 5 system implant was a technological breakthrough for hearing in noisy conditions by an electrical stimulation of the deaf cochlea. Being compatible with previous $\mathrm{Cl}$, upgrading Nucleus ${ }^{\circledR} 24$ with $\mathrm{CP} 810$ noise program improved by more than $20 \%$ performance in $77 \%$ of users, thanks to the two adaptive omni-directional microphones and new front-end processing options[5]. In the Nucleus 6 (CP 900 series), an automatic signal processing algorithm (SCAN) has been added allowing automatic transition between six scenes based on the analysis of environmental signal. Because $\mathrm{Cl}$ is a highly reliable implanted device (cumulative survival percentage of $92.1 \%$ over 29 years for CI22M reported by the company)[10], reimplantation would not be necessary to upgrade ancient $\mathrm{CI} 22 \mathrm{M}$ devices which have been implanted more than 20 years ago with new technologies if also compatible. Once made possible, upgrading the old $\mathrm{Cl}$ with the compatible new generation CP900 SP, yielded to significant improvement in noise intelligibility for more than half of $\mathrm{CI} 22 \mathrm{M}$ users in a short period of time. The 
number of $\mathrm{Cl} 22 \mathrm{M}$ implantees who reached the level of intelligibility in noise using the Framatix test increased from $39 \%$ to $58 \%$ with previous SPs and CP900 SP, respectively and most patients prefer new automatic algorithms. No change was observed in quiet regardless of the test used. These results confirm a study including two groups of 15 and $24 \mathrm{CI} 22 \mathrm{M}$ recipients recruited from six North American clinics, showing no change in quiet for CNC words but speech intelligibility improvement in noise with the CP900 compared with the Freedom SP, for AzBio sentences at fixed signal-to-noise ratio [11]. This suggests that after such a long duration of cochlear implantation, the frequency mapping should be located in the auditory cortex which may allow a rapid adaptation to new coding strategy and audiological technology. However, the patients implanted more than 20 years ago were different from those who have been implanted more recently and have already benefit from new technologies. Early $\mathrm{Cl}$ candidates with a prelingual deafnesswere implanted later than nowadays, a critical period for hearing maturation [12]. Further post-lingual $\mathrm{Cl}$ users had a more profound deafness and for longer time than during the last 10 years [13]. This may explain that, before upgrade, only $54 \%$ of $\mathrm{Cl}$ recipients in quiet and $39 \%$ in noise were able to perform adaptive tests which are more sensitive to show a benefit with the new SP but also more difficult. Moreover, the benefit in noise of upgrading $\mathrm{CI} 22 \mathrm{M}$ with $\mathrm{CP} 900$ appears to be less striking than upgrading Nucleus ${ }^{\circledR} 24$ with CP810 [5] and APHAB questionnaire was probably not sensitive enough to capture a weaker subjective benefit.

\section{Conclusion}

More than half of the upgraded old $\mathrm{Cl}$ recipients with a compatible recent SP performed better the difficult Framatix test in quiet and noise in a short period of 
time. Although it was thought that reimplantation of the internal receiver should be necessary several times during life-spanning of the majority of profound to total deaf patients, this study evidences that cochlear implantation would be performed only once, especially in children operated on nowadays before 1 year old.

\section{References}

1. Kral A, Kronenberger WG, Pisoni D, et al (2016) Neurocognitive factors in sensory restoration of early deafness: a connectome model. Lancet Neurol 15:610-21. https://doi: 10.1016/S1474-4422(16)00034-X.

2. Livingston G, Sommerlad A, Orgeta V, et al (2017) Dementia prevention, intervention, and care. Lancet 390 (10113):2673-734. https://doi: 10.1016/ S0140-6736(17)31363-6.

3. Mosnier I, Vanier A, Bonnard D, et al. (2018) Long-term cognitive prognosis of profoundly deaf older adults after hearing rehabilitation using cochlear implants: cognitive prognosis after hearing rehabilitation. J Am Geriatr Soc 66(8):1553-61. https://doi: 10.1111/jgs.15445.

4. Wilson BS and Dorman MF (2008) Cochlear implants: a remarkable past and a brilliant future. Hearing Res 242(1-2):3-21. https://doi: 10.1016/j

5. Mosnier I, Marx M, Venail F, Loundon N, Roux-Vaillard S, Sterkers O (2014). Benefits from upgrade to the CP810 Sound Processor for Nucleus 24 Cochlear implant recipients. Eur Arch Otorhinolaryngol 271(1): 49-57. https://doi: 10.1007/s00405-013-2381-8. 
6. Mosnier I, Mathias N, Flament J, et al. (2017) Benefit of the UltraZoom beamforming technology in noise in cochlear implant users. Eur Arch Otorhinolaryngol. 274(9): 3335-3342. https://doi: 10.1007/s00405-017-4651-3.

7. Franco-Vidal V, Parietti-Winkler C, Guevara N, et al. (2020) The Oticon Medical Neuro Zti cochlear implant and the Neuro 2 sound processor: multicentric evaluation of outcomes in adults and children. Int J Audiol. 59(2):153-160. https://doi: 10.1080/14992027.

8. Jansen S, Luts H, Wagener KC, et al. (2012) Comparison of three types of French speech-in-noise tests: A multi-center study. Int J Audiol 51(3): 164 -73. https:// doi: $10.3109 / 14992027$.

9. Cox RM and Alexander GC. The abbreviated profile of hearing aid benefit. Ear Hear 1995; 16: 176-186.

10. Cochlear ${ }^{\text {mm }}$ Nucleus ${ }^{\circledR}$ reliability report June 2019. https: //www.cochlear.com

11. Biever A, Gilden J, Zwolan T et al. (2018) Upgrade to Nucleus 6 in previous generation Cochlear sound processor recipients. J Am Acad Audiol 29: 802-813.

12. Bruijnzeel H, Bezdjian A, Lesinski-Schiedat A et al. (2017) Evaluation of pediatric cochlear implant care throughout Europe: Is European pediatric cochlear implant care performed according to guidelines?

13. Holder JT, Reynolds SM, Sunderhaus LW, Gifford RH. (2018) Current profile of adults presenting for preoperative cochlear implant evaluation. Trends in Hearing, 22: 1-16.

\section{Figure legend}


Figure 1: Performance using Framatrix in quiet $(A, n=18)$ and in noise $(B, n=19)$ of Cl 22 M recipients upgraded with CP900. In noise, evaluation was made in 13 patients before upgrade with previous SP, and became possible in 6 additional patients with CP 900 SP. Results are expressed as the speech reception thresholds (SRT, dB). The box plots show the first and third quartiles values and the central line the median value. Comparisons were made using Wilcoxon paired tests. Significances were considered at a $\mathrm{p}$ value $<0.05$.

Figure 2: $A$ PHAB scores of $\mathrm{Cl} 22 \mathrm{M}$ recipients upgraded with CP900. The box plots show the first and third quartiles values and the central line the median value. Comparisons were made using Wilcoxon paired tests. No change of the scores was observed after upgrade. 
Table 2: Sound processing features of the processor types evaluated in the study. 


\begin{tabular}{c|ccc} 
Speech processors & Esprit 3GTM & Freedom ${ }^{\mathrm{TM}}$ & CP 900TM \\
\hline Microphones & Dual port directional & Dual port + omnidirectional & $\begin{array}{r}\text { Two matched } \\
\text { omnidirectional }\end{array}$ \\
Frequency range (Hz) & $75-10823$ & $188-7980$ & $63-7938$ \\
Default IIDR (dB) & 30 & 40 & 40 \\
$\begin{array}{c}\text { SmartSound (front- } \\
\text { end processing) } \\
\text { options }\end{array}$ & $\begin{array}{c}\text { Auto-sensitivity } \\
\text { WhisperTM }\end{array}$ & $\begin{array}{c}\text { Auto-sensitivity, WhisperTM, } \\
\text { ADRO, Beam }\end{array}$ & $\begin{array}{c}\text { Auto-sensitivity, WhisperTM, } \\
\text { ADRO, Beam, Zoom }\end{array}$ \\
NMR, SNR-
\end{tabular}

Autosensitivity: automatic sensitivity control which reduces the sensitivity of the microphone based on the level of detected background noise;

Whisper: algorithm which extend the lower limit of the IIDR in order to improve access to quiet speech;

ADRO: adaptive dynamic range optimization algorithm which regulates individual channel gains to improve comfort and intelligibility

Beam: adaptive algorithm which modifies its polar characteristics according to direction of the dominant sound source;

Zoom: strong directional response, similar to Beam, but fixed rather than adaptive

SNR-NR (Signal-to-Noise Ratio based Noise Reduction): attenuate steady-state background noises irrespective of the direction to reduce instantaneously background noise levels

WNR (Wind Noise Reduction): algorithm to reduce the low frequency noise from wind

SCAN: automatic analyze of the environmental signal classified in 6 scenes (quiet, noise, speech, speech in noise, wind or music) allowing an automatic transition between these 6 scenes. 